\title{
Oral Health-Related Quality of Life
}

\section{among an Australian sample of people}

\author{
who inject drugs
}




\section{Abstract}

Objectives: People who inject drugs (PWID) have poor oral health. However, their Oral HealthRelated Quality of Life (OHRQoL) is unknown. Our study was designed to measure the OHRQoL of PWID.

Methods: The Oral Health Impact Profile-14 (OHIP-14) was administered to 794 PWID recruited in Australian capital cities as part of the 2013 Illicit Drug Reporting System. Three OHIP-14 summary indicators were examined: 'Prevalence' (proportion reporting $\geq 1$ item at least 'fairly often'), 'severity' (mean total OHIP-14 score), and 'extent' (number of impacts reported at least 'fairly often'). Associations between 'prevalence' and 'extent' and variables drawn from the health, drug use and social domains were investigated.

Results: All OHIP-14 summary indicators among IDRS participants were significantly higher than in the general Australian population. In multivariate analysis, the 'prevalence' indicator was significantly and positively associated with female gender ( $A O R=1.75,95 \% \mathrm{Cl} 1.27-2.38$ ), those born in Australia ( $A O R=2,95 \% \mathrm{Cl} 1.25-3.23-$ ), not completing Year 10 compared to those who had completed Year 12 or a higher qualification ( $A O R=1.59,95 \% \mathrm{Cl} 1.03-2.44)$, and methadone treatment $(A O R=1.61,95 \% \mathrm{Cl} 1.14-2.29)$. The 'extent' indicator was significantly and positively associated with female gender (AIRR=1.56, 95\% $\mathrm{Cl} 1.19-2.08)$, unemployment ( $\mathrm{AIRR}=1.59,95 \% \mathrm{Cl}$ 1.01-2.44) and having an injecting career of $10-20$ years (AIRR $=1.76,95 \% \mathrm{Cl} 1.03-3.01$ ).

Conclusions: PWID have poorer OHRQoL than the Australian general population. Poor OHRQoL was particularly common in female PWID and those with longer injecting careers. Interventions to improve the oral health of PWID may improve their OHRQoL.

Key Words: substance abuse, intravenous; oral health; oral hygiene; Quality of Life; dental care; OHRQoL; Australia 
Truong, A., Higgs, P., Cogger, S., Burns, L., Jamieson, L. \& Dietze, P. 2015. Oral Health-Related Quality of Life among an

\section{Introduction}

People who inject drugs (PWID) are much more likely to experience dental problems, such as caries and missing and/or filled teeth (1-4), than members of the wider population (1). This is thought to be due to a range of factors including unstable accommodation (5), poor oral hygiene habits (6) and physiological effects of drug use such as xerostomia or 'dry mouth' $(2,7,8)$, bruxism (involving teeth grinding or jaw clenching) $(5,9)$, the analgesic effects of opioids and their ability to mask pain (therefore delaying treatment until conditions become serious) $(5,10)$ and impaired recovery from oral diseases as a result of opioid use (11). Poor oral health has not only been found to be associated with serious health conditions such as cardiovascular disease (12), coronary heart disease (13) and respiratory diseases (14), but is related to wider health and social problems such as speech impediments, poor nutrition and low self-image (15). This highlights the importance of these issues for PWID, and the need to better understand the impact of these effects.

Measures that recognise a person's subjective perspective of how their oral health affects their overall health and wellbeing (16) have been developed under the rubric of Oral Health-Related Quality of Life (OHRQoL). The assessment of OHRQoL helps define treatment goals that focus on a person's physical functioning as well as their social and emotional experiences. Comparing OHRQoL between specific populations allows us to capture the reality of day to day life for people with a chronic condition, such as poor oral health, that is relevant to different contexts, providing important information for healthcare providers, policy makers and patients (16). OHRQoL has been examined in specific subgroups; for example, people experiencing homelessness have dramatically lower OHRQoL than the broader population $(17,18)$. However, to our knowledge there are no published studies of OHRQoL among PWID who, as indicated above, are a highly marginalised population with known high prevalence of dental health problems. Evidence about OHRQoL would allow the development of clearer strategies for ameliorating this burden, for example by enabling 
Truong, A., Higgs, P., Cogger, S., Burns, L., Jamieson, L. \& Dietze, P. 2015. Oral Health-Related Quality of Life among an Australian sample of people who inject drugs, Journal of Public Health Dentistry, doi: 10.1111/jphd.12092

policy makers to assess the need for and benefits of incorporating dental health in PWID-specific services $(16,19)$.

The aim of this study was to measure the OHRQoL of regular PWID recruited from capital cities across Australia. In this paper, we describe the OHRQoL of this population in the context of Australian norms using a standardised instrument that measures OHRQoL. We also compare findings to a sample of homeless people in South Australia, as homeless people are a group known to report poor OHRQoL $(17,18)$. We then examine associations between OHRQoL and a range of demographic and drug use variables.

\section{Methods}

Sample and interviews

Data were drawn from surveys of 887 PWID conducted in all Australian capital cities as part of the 2013 Illicit Drug Reporting System (IDRS). One component of the IDRS involves an annual crosssectional survey of PWID, typically undertaken over June-August. Eligible participants were required to be aged at least 18 years, to report injecting drug use (IDU) at least once per month in the six months before interview, be proficient in English and to have lived in the capital city of recruitment for the preceding 12 months (20). Participants were recruited through posted advertisement at needle and syringe programs (NSPs) in each capital city as well as through snowballing and word of mouth (20). Participants were administered a structured, face-to-face questionnaire designed to gather detailed information on demographics, drug use and various related health outcomes that took approximately one hour to complete. Further details on the study can be found elsewhere (20).

\section{Outcome variables}


Truong, A., Higgs, P., Cogger, S., Burns, L., Jamieson, L. \& Dietze, P. 2015. Oral Health-Related Quality of Life among an Australian sample of people who inject drugs, Journal of Public Health Dentistry, doi: 10.1111/jphd.12092

The Oral Health Impact Profile (OHIP) is a validated patient-oriented instrument that measures OHRQoL; the short version of this instrument, the Oral Health Impact Profile - 14 (OHIP-14), is often used in population-level studies. Outcome variables were derived from the OHIP-14 (21) included in the 2013 IDRS questionnaire. The OHIP-14 is comprised of 14 items that measure the negative impacts on physical, psychological and social dimensions resulting from problems relating to the mouth, teeth and dentures. The OHIP-14 enhances our understanding of the relationship between general health and oral health by allowing measurement of the quality of an individual's wellbeing as related to their dental health, as it extends beyond simply counting or measuring problematic dental conditions (16).

Participants were asked how often they experienced a particular negative impact due to their oral health in the past three months. For example, the first item asks "How often during the last three months have you had trouble pronouncing any words because of problems with your teeth, mouth or dentures?" Five point rating scales are used for each item: from 'Never', 'Hardly ever', 'Occasionally', 'Fairly often' to 'Very often' that are subsequently assigned the scores of 0, 1, 2, 3 and 4 respectively (22).

Three summary indicators were generated from the OHIP-14 (see Table 1), as used in previous research (21):

1. 'Prevalence': The percentage of people reporting one or more of 14 items 'fairly often' or 'very often'. Responses were dichotomised into two groups (i.e. only responses coded as 3 or 4 were counted for 'prevalence');

2. 'Severity': The sum of a participant's ordinal responses, which can range from 0 to 56 , with higher scores reflecting poorer OHRQoL; and

3. 'Extent': The number of impacts (items) reported at least 'fairly often'.

\section{Potential correlates}


Truong, A., Higgs, P., Cogger, S., Burns, L., Jamieson, L. \& Dietze, P. 2015. Oral Health-Related Quality of Life among an Australian sample of people who inject drugs, Journal of Public Health Dentistry, doi: 10.1111/jphd.12092

Associations between a range of demographic and drug use variables and OHIP-14 scores were examined. The independent variables reflect those used in similar studies with the same population group and are listed in Table 2, along with the categorisations used in analysis (23). The categorisations are self-explanatory except for the following. Average weekly income was coded to reflect the 'low income' referent used by the Australian Bureau of Statistics (24); as seen in Tables 2 and 3, the '\$400+' variable was used to define amounts higher than 'low income'; the methamphetamine use variable categories (MA use frequency) included the three forms available in Australia - ice (crystalline), speed (powder) and base (damp or oily substance); the 'Other' category for less frequent responses to 'Drug injected most often last month' included pharmaceutical opioids such as methadone, buprenorphine, buprenorphine-naloxone, morphine and oxycodone, as well as cocaine, benzodiazepines and other combination drug cocktails; and the 'Other' category for 'Drug of choice' included pharmaceutical opioids such as methadone, buprenorphine, buprenorphinenaloxone, morphine and oxycodone and other opioids not listed, as well as cocaine, LSD, ecstasy, benzodiazepines, alcohol, cannabis and other drugs not listed.

\section{Analysis}

All cases with non-missing values for each outcome and predictor variable were included in the dataset, producing a final sample of 794. Descriptive statistics were generated for the three summary indicators of the OHIP-14 and were compared with the latest available OHIP-14 results for the Australian general population (2004-2006 National Survey of Adult Oral Health (NSAOH)). To enable comparison with another group with known poor oral health (25) and lower OHIP-14 scores than the general population $(17,18)$ summary indicators were also compared with a sample of homeless people in South Australia (SA). Stata ${ }^{\circledR} 11.0$ was used to perform all analyses.

Associations between the independent variables and 'prevalence' were investigated using multivariate logistic regression. Negative binomial regression was chosen for the equivalent analysis 
Truong, A., Higgs, P., Cogger, S., Burns, L., Jamieson, L. \& Dietze, P. 2015. Oral Health-Related Quality of Life among an Australian sample of people who inject drugs, Journal of Public Health Dentistry, doi: 10.1111/jphd.12092

of the 'extent' variable, as initial analysis showed that these data were over-dispersed (26). Initial inspection of the 'severity' variable revealed many zero scores that highly skewed the distribution, precluding further examination of this outcome.

The same independent variables were included for both bivariate and multivariate analyses of 'extent' and 'prevalence'. Statistical significance was set at the $p<0.05$ level. For the logistic regression models, results were reported as odds ratios (OR) and adjusted odds ratios (AOR); for the negative binomial regression models, results were reported as incidence rate ratios (IRR) and adjusted incidence rate ratios (AIRR).

\section{Ethics}

Ethical approvals for this study were obtained from Human Research Ethics Committees of the [blinded for review], and the overall IDRS study is approved by the [blinded for review] Human Research Ethics Committee.

\section{Results}

Overall OHIP scores and summary indicators

Table 1 shows that this sample of PWID fared significantly worse on all three OHIP-14 summary indicators than the general Australian population (27). However, IDRS participants had significantly lower scores across all OHIP measures than a population of homeless people in South Australia (17, 18). 
Truong, A., Higgs, P., Cogger, S., Burns, L., Jamieson, L. \& Dietze, P. 2015. Oral Health-Related Quality of Life among an Australian sample of people who inject drugs, Journal of Public Health Dentistry, doi: 10.1111/jphd.12092

\section{Correlates of OHIP-14 'prevalence'}

Table 2 shows that a range of variables were associated with 'prevalence' at a bivariate level. However, after adjusting for all of the variables included in the model, only a few significant associations remained. 'Prevalence' was higher among females than males, as it was for those who were born in Australia compared to those born outside Australia. Participants who completed Year 12 or a higher qualification were more likely to report 'prevalence' when compared to those who did not complete Year 10. A greater proportion of participants who reported being on methadone maintenance treatment at the time of their interview reported 'prevalence' than those who were not on any form of drug treatment.

Table 2 about here

\section{Correlates of OHIP-14 'extent'}

Table 3 shows that a range of variables were associated with 'extent' at a bivariate level. However, after adjusting for all variables included in the model, only a few associations remained.

In multivariate analysis, the 'extent' scores of females were higher than those of males, as were the 'extent' scores of those who were unemployed compared to those who were employed. Participants who reported an injecting career of between 10 and 20 years had higher 'extent' scores than those who reported injecting for less than 10 years.

\section{Discussion}


Truong, A., Higgs, P., Cogger, S., Burns, L., Jamieson, L. \& Dietze, P. 2015. Oral Health-Related Quality of Life among an Australian sample of people who inject drugs, Journal of Public Health Dentistry, doi: 10.1111/jphd.12092

OHRQoL, as measured by OHIP-14 scores, was significantly worse among our sample of Australian PWID than the general population. Nevertheless, scores were not as low as in a sample of homeless people recruited in South Australia (17). Interestingly, when accommodation status was entered into our regression analyses, participants who reported 'no fixed address' generally showed poorer OHRQoL than other participants, but this difference failed to reach significance. This probably reflects the relatively small number of participants who reported 'no fixed address' in our sample, and an associated lack of statistical power to detect any effects.

We also found a consistent pattern of poorer OHRQoL among females in our study. This finding contrasts with previous Australian research undertaken by Sanders et al. who found no statistically significant gender differences in OHIP-14 results (28). Previous research highlights poor oral health among PWID (1). Our findings suggest that subjective perceptions and life impacts of this poor oral health, such as feeling self-conscious when interacting with others, may be worse for female than for male PWID. This would be consistent with gender-based issues around body image more generally, which show that poor body image impacts more on females than males (29).

Being employed at the time of interview was significantly associated with reporting fewer OHIP-14 items 'fairly often' or 'very often' (the 'extent' measure). This finding is consistent with that of Shekarchizadeh et al. (30) who found that among people who used drugs, those who were unemployed had the poorest oral health behaviours. Employment is a marker of higher socioeconomic status among PWID. We found consistent effects of higher socioeconomic status, with those who reported completing Year 12 or a higher qualification being less likely to report 'prevalence' than those who did not complete Year 10. These findings are consistent with other research showing higher rates of dental service utilisation among more highly educated groups in the community (31). 
Truong, A., Higgs, P., Cogger, S., Burns, L., Jamieson, L. \& Dietze, P. 2015. Oral Health-Related Quality of Life among an

We found that PWID who were born in a country other than Australia were less likely to report 'prevalence' after adjusting for the effects of other variables. We were unable to disaggregate this variable further, however, with over 11 different countries of birth reported by participants. Further research focusing on specific dental health practices by PWID of different ethnicities is required to better understand this relationship.

Interestingly, frequencies of heroin or methamphetamine use were not significantly associated with poorer OHRQoL, suggesting that lifestyle factors and personal circumstances are more important for OHRQoL for PWID than drug types used and the physiological effects associated with them. However, it should be noted that the specific oral health effects of different drug types may be masked by the fact that many participants in the IDRS sample have long histories of polydrug injection (20).

Even after adjusting for age, we found that an injecting career of between 10 and 20 years to be significantly associated with the 'extent' outcome when compared with an injecting career of less than 10 years (with a similar, non-significant, pattern evident for 'prevalence'). However, although the pattern was similar, the differences between an injecting career of more than 20 years and a career of less than 10 years failed to reach significance. These findings contrast with those of Laslett et al. (1) who found that injecting career was not related to dental problems. However, Laslett et al. examined only past-year dental problems, whereas our findings suggest that it is the cumulative effect of a longer injecting career on oral health that may lead to sustained impacts on OHRQoL.

We found that participants in current methadone treatment were significantly more likely to report poorer OHRQoL than those not in drug treatment (Table 2). This relationship was maintained even after adjusting for type and frequency of other drug use. Previous research has shown that people in current methadone treatment exhibit poor dental health $(4,32)$ and poor oral health behaviours (i.e. not brushing teeth, not flossing, and eating sugary products) (30), but there is no evidence to 
Truong, A., Higgs, P., Cogger, S., Burns, L., Jamieson, L. \& Dietze, P. 2015. Oral Health-Related Quality of Life among an Australian sample of people who inject drugs, Journal of Public Health Dentistry, doi: 10.1111/jphd.12092

suggest that their oral health behaviour would be worse compared to those not in treatment. Further, the formulation of methadone for Australian programs changed in July 1994 (sorbitol replaced sucrose, rendering the preparation sugar-free) in response to concerns about its high sugar content (33), meaning that sugar exposure through methadone delivery is unlikely to underpin any differences. Further work is needed to unpack and understand the relationship between methadone treatment utilisation and OHRQoL we observed.

The OHIP-14 module used in this study was limited to outcomes experienced by participants in the preceding three months. Additionally, although the IDRS survey is designed to be easily understood, recall bias remains a possible limitation, together with the subjective nature of the OHIP-14 in relation to assessing the social impacts of oral health. Further, as with most research involving PWID, the nature of the recruitment and sampling used in this study means that it is not possible to determine the extent to which the IDRS sample are representative of PWID more broadly (20).

\section{Conclusion}

Our study indicates that PWID have significantly poorer OHRQoL than the Australian general population. PWID need access to high-quality and timely dental services, ideally involving people skilled in working with vulnerable populations, to improve their OHRQoL. However, our study shows a range of factors are related to the OHRQoL of PWID such as education, employment and length of injecting career. These factors should be taken into consideration in policy and practice, for example through enhancing existing PWID-specific primary care or related services, with a specific focus on the OHRQoL of female PWID. These findings form an important step forward toward further research to develop interventions to improve this essential aspect of overall health and wellbeing of PWID. 


\section{References}

1. Laslett A-M, Dietze P, Dwyer R. The oral health of street-recruited injecting drug users: prevalence and correlates of problems. Addiction. 2008;103(11):1821-5.

2. Brown C, Krishnan S, Hursh K, Yu M, Johnson P, Page K, et al. Dental disease prevalence among methamphetamine and heroin users in an urban setting. J Am Dent Assoc. 2012;143(9):9921001.

3. D'Amore MM, Cheng DM, Kressin NR, Jones J, Samet JH, Winter M, et al. Oral health of substance-dependent individuals: impact of specific substances. J Subst Abuse Treat. 2011;41(2):179-85.

4. Reece AS. Dentition of addiction in Queensland: poor dental status and major contributing drugs. Aust Dent J. 2007;52(2):144-9.

5. Robinson PG, Acquah S, Gibson B. Drug users: oral health-related attitudes and behaviours. Br Dent J. 2005;198(4):219-24.

6. Shetty V, Mooney $\mathrm{L}$, Zigler CM, Belin TR, Murphy D, Rawson R. The relationship between methamphetamine use and increased dental disease. J Am Dent Assoc. 2010;141(3):307-18.

7. Hamamoto DT, Rhodus NL. Methamphetamine abuse and dentistry. Oral Dis. 2009;15(1):2737.

8. Molendijk B, Ter Horst G, Kasbergen M, Truin GJ, Mulder J. Dental health in Dutch drug addicts. Community Dent Oral Epidemiol. 1996;24(2):117-9.

9. Winocur E, Gavish A, Volfin G, Halachmi M, Gazit E. Oral motor parafunctions among heavy drug addicts and their effects on signs and symptoms of temporomandibular disorders. J Orofac Pain. 2001;15(1):56-63.

10. Rosenstein DI. Effect of long-term addiction to heroin on oral tissues. J Public Health Dent. 1975;35(2):118-22.

11. Eisch AJ, Mandyam CD. Drug dependence and addiction, II: Adult neurogenesis and drug abuse. Am J Psychiatry. 2004;161(3):426.

12. Fowler EB, Breault LG, Cuenin MF. Periodontal disease and its association with systemic disease. Mil Med. 2001;166(1):85-9.

13. Loesche WJ. Periodontal disease: link to cardiovascular disease. Compend Contin Educ Dent. 2000;21(6):463-6, 8, 70 passim; quiz 84.

14. Scannapieco FA, Ho AW. Potential associations between chronic respiratory disease and periodontal disease: analysis of National Health and Nutrition Examination Survey III. J Periodontol. 2001;72(1):50-6.

15. Metsch LR, Crandall L, Wohler-Torres B, Miles CC, Chitwood DD, McCoy CB. Met and unmet need for dental services among active drug users in Miami, Florida. J Behav Health Serv Res.

2002;29(2):176-88. 
16. Sischo L, Broder HL. Oral health-related quality of life: what, why, how, and future implications. J Dent Res. 2011;90(11):1264-70.

17. Parker E, Jamieson LM, Steffens M, Cathro P, Logan R. Oral Health Related Quality of Life of Homeless Adults. IADR General Session; 16 July; Barcelona, Spain. Adelaide, Australia: University of Adelaide; 2010 July.

18. Parker E, Jamieson LM, Steffens MA, Cathro P, Logan R. Self-reported oral health of a metropolitan homeless population in Australia: Comparisons with population-level data. Aust Dent J. 2011;56:272-7.

19. Kimber J, Mattick RP, Kaldor J, van Beek I, Gilmour S, Rance JA. Process and predictors of drug treatment referral and referral uptake at the Sydney Medically Supervised Injecting Centre. Drug Alcohol Rev. 2008;27(6):602-12.

20. Stafford J, Burns L. Australian Drug Trends 2013. Findings from the Illicit Drug Reporting System (IDRS). Sydney: National Drug and Alcohol Research, University of New South Wales, 2014. 21. Slade GD. Derivation and validation of a short-form oral health impact profile. Community Dent Oral Epidemiol. 1997;25(4):284-90.

22. Slade GD. The Oral Health Impact Profile. In: Slade GD, editor. Measuring Oral Health and Quality of Life. Chapel Hill: University of North Carolina; 1997. p. 93-104.

23. Dietze $P$, Stoove M, Miller $P$, Kinner S, Bruno R, Alati R, et al. The self-reported personal wellbeing of a sample of Australian injecting drug users. Addiction. 2010;105(12):2141-8.

24. Australian Bureau of Statistics. Household Income and Income Distribution - Australia 200910. Canberra: Australian Bureau of Statistics, 2011.

25. Robbins JL, Wenger L, Lorvick J, Shiboski C, Kral AH. Health and oral health care needs and health care-seeking behavior among homeless injection drug users in San Francisco. J Urban Health. 2010;87(6):920-30.

26. Cameron AC, Trivedi, P. K. Chapter 3: Basic Count Regression. In: Hammond P, Holly, A, editor. Regression Analysis of Count Data. New York: Cambridge University Press; 1998. p. 59 - 95. 27. Crocombe LA, Mahoney GD, Spencer AJ, Waller M. Will improving access to dental care improve oral health-related quality of life? Aust Dent J. 2013;58(2):192-9.

28. Sanders AE, Spencer AJ. Job characteristics and the subjective oral health of Australian workers. Aust N Z J Public Health. 2004;28(3):259-66.

29. Page RM, Scanlan A, Allen O. Adolescent Perception of Body Weight and Attractiveness. J Child Adoles Subst. 1995;4(4):43-56.

30. Shekarchizadeh H, Khami MR, Mohebbi SZ, Virtanen JI. Oral health behavior of drug addicts in withdrawal treatment. BMC Oral Health. 2013;13:11.

31. Spencer AJ, Harford J. Dental visiting among the Australian adult dentate population. Aust Dent J. 2007;52(4):336-9.

32. Coates EA, Brennan D, Logan RM, Goss AN, Scopacasa B, Spencer AJ, et al. Hepatitis C infection and associated oral health problems. Aust Dent J. 2000;45(2):108-14.

33. Sheedy JJ. Methadone and caries. Case reports. Aust Dent J. 1996;41(6):367-9. 
Truong, A., Higgs, P., Cogger, S., Burns, L., Jamieson, L. \& Dietze, P. 2015. Oral Health-Related Quality of Life among an

Table 1: OHIP-14 Summary Indicators

\begin{tabular}{lllllll}
\hline & \multicolumn{2}{l}{$\begin{array}{l}2013 \\
(n=794)\end{array}$} & \multicolumn{2}{l}{$\begin{array}{l}2004-06 \\
(n=3295)\end{array}$} & $95 \% \mathrm{Cl}$ & \multicolumn{2}{l}{$\begin{array}{l}\text { SA Homeless } \neq \\
(\mathrm{n}=248)\end{array}$} \\
\hline Prevalence & $\%$ & $95 \% \mathrm{Cl}$ & $\%$ & 95 & $95 \% \mathrm{Cl}$ \\
& 48 & $(45-52)$ & 19 & $(17-21)$ & 91 & $(87-95)$ \\
Extent & mean & $95 \% \mathrm{Cl}$ & mean & $95 \% \mathrm{Cl}$ & mean & $95 \% \mathrm{Cl}$ \\
& 2.5 & $(2.2-2.7)$ & 0.5 & $(0.4-0.6)$ & 9.3 & $(8.7-9.9)$ \\
Severity & mean & $95 \% \mathrm{Cl}$ & mean & $95 \% \mathrm{Cl}$ & mean & $95 \% \mathrm{Cl}$ \\
& 13.5 & $(12.5-14.5)$ & 7.6 & $(7.1-8.1)$ & 21.6 & $(19.8-23.4)$ \\
\hline
\end{tabular}

Sources:

†Crocombe et al. (2013), weighted data presented (27)

‡ Parker et al. (2010)(17) 
Truong, A., Higgs, P., Cogger, S., Burns, L., Jamieson, L. \& Dietze, P. 2015. Oral Health-Related Quality of Life among an Australian sample of people who inject drugs, Journal of Public Health Dentistry, doi: 10.1111/jphd.12092

Table 2: Distribution of 'prevalence' scores across key sociodemographic and drug use variables, along with logistic regression results.

\begin{tabular}{|c|c|c|c|c|c|c|c|}
\hline $\begin{array}{l}\mathrm{n}=794 \\
\text { Gender }\end{array}$ & & \multicolumn{2}{|c|}{$\begin{array}{l}\text { n(\%) Report } \\
\text { 'prevalence' }\end{array}$} & \multicolumn{2}{|c|}{ OR $(95 \% \mathrm{Cl})$} & \multicolumn{2}{|c|}{ AOR $(95 \% \mathrm{Cl})$} \\
\hline & Female & 161 & (56) & Ref. & & & \\
\hline & Male & 223 & (44) & $\underline{0.61}$ & $(0.45-0.81)$ & $\underline{0.57}$ & $(0.42-0.79)$ \\
\hline \multicolumn{8}{|l|}{ Age } \\
\hline & $<30$ & 37 & (43) & Ref. & & & \\
\hline & $30-39$ & 133 & (46) & 1.14 & $(0.70-1.85)$ & 1.08 & $(0.56-2.09)$ \\
\hline & $40+$ & 214 & (51) & 1.38 & $0.86-2.20)$ & 1.60 & $(0.71-3.62)$ \\
\hline \multicolumn{8}{|c|}{ Accommodation } \\
\hline & Stable & 289 & (48) & Ref. & & & \\
\hline & Unstable & 41 & (41) & 0.74 & $(0.48-1.13)$ & 0.71 & $(0.45-1.13)$ \\
\hline & Homeless & 54 & (55) & 0.97 & $(0.70-1.34)$ & 1.33 & $(0.84-2.13)$ \\
\hline \multicolumn{8}{|c|}{ Country of birth } \\
\hline & Australia & 346 & (51) & Ref. & & & \\
\hline & Other & 38 & (35) & $\underline{0.52}$ & $(0.34-0.79)$ & $\underline{0.50}$ & $(0.31-0.80)$ \\
\hline \multicolumn{8}{|c|}{ Language spoken at home } \\
\hline & English & 375 & (49) & Ref. & & & \\
\hline & Other & 9 & $(27)$ & $\underline{0.39}$ & $(0.18-0.84)$ & 0.51 & $(0.22-1.17)$ \\
\hline \multicolumn{8}{|l|}{ ATSI } \\
\hline & No & 315 & $(48)$ & Ref. & & & \\
\hline & Yes & 69 & (51) & 1.16 & $(0.80-1.69)$ & 0.90 & $(0.60-1.35)$ \\
\hline \multicolumn{8}{|c|}{ Highest level of education } \\
\hline & $<$ Year 10 & 149 & (54) & Ref. & & & \\
\hline & Year 10-11 & 165 & (46) & $\underline{0.73}$ & $(0.53-0.99)$ & 0.74 & $(0.53-1.04)$ \\
\hline & Year 12/higher/trade & 70 & (42) & $\underline{0.62}$ & $(0.42-0.91)$ & $\underline{0.63}$ & $(0.41-0.97)$ \\
\hline \multicolumn{8}{|c|}{ Employment } \\
\hline & No & 349 & (50) & Ref. & & & \\
\hline & Yes & 35 & (39) & 0.65 & $(0.41-1.01)$ & 0.68 & $(0.42-1.12)$ \\
\hline \multicolumn{8}{|c|}{ Income (average weekly amount) } \\
\hline & $0-249$ & 113 & (50) & Ref. & & & \\
\hline & 250-399 & 144 & (47) & 0.89 & $(0.63-1.26)$ & 0.84 & $(0.58-1.22)$ \\
\hline & $400+$ & 127 & (49) & 0.99 & $(0.69-1.41)$ & 0.95 & $(0.64-1.41)$ \\
\hline \multicolumn{8}{|c|}{ Age first injected } \\
\hline & Continuous & & & 1.00 & $(0.98-1.02)$ & 1.00 & $(0.97-1.04)$ \\
\hline \multicolumn{8}{|c|}{ Length of injecting career } \\
\hline & $<10$ years & 38 & (37) & Ref. & & & \\
\hline & $10-20$ years & 161 & (52) & $\underline{1.83}$ & $(1.16-2.90)$ & 1.83 & $(0.97-3.44)$ \\
\hline & $>20$ years & 185 & (48) & $\overline{1.57}$ & $(1.00-2.47)$ & 1.35 & $(0.59-3.10)$ \\
\hline \multicolumn{8}{|c|}{ Drug of choice } \\
\hline & Heroin & 212 & (50) & Ref. & & & \\
\hline & Other & 104 & (53) & 1.12 & $(0.80-1.57)$ & 1.32 & $(0.84-2.08)$ \\
\hline & Methamphetamine & 68 & (39) & $\underline{0.62}$ & $(0.44-0.89)$ & 0.60 & $(0.34-1.09)$ \\
\hline \multicolumn{8}{|c|}{ Drug injected most often last month } \\
\hline & Heroin & 169 & (52) & Ref. & & & \\
\hline & Other & 126 & (48) & 0.85 & $(0.62-1.18)$ & 1.07 & $(0.62-1.85)$ \\
\hline & Methamphetamine & 89 & (44) & 0.73 & $(0.51-1.04)$ & 0.97 & $(0.48-1.95)$ \\
\hline MA use & (last 6 months) & & & & & & \\
\hline & No use & 145 & (49) & Ref. & & & \\
\hline & $<$ Fortnightly & 84 & (46) & 0.88 & $(0.61-1.28)$ & 0.99 & $(0.67-1.48)$ \\
\hline & Fortnightly or more & 155 & (49) & 0.98 & $(0.71-1.34)$ & 1.48 & $(0.96-2.28)$ \\
\hline Heroin & ncy (last 6 months) & & & & & & \\
\hline & No use & 143 & $(45)$ & Ref. & & & \\
\hline & $<$ Fortnightly & 42 & (43) & 0.89 & $(0.56-1.40)$ & 0.83 & $(0.51-1.36)$ \\
\hline & Fortnightly or more & 199 & (52) & 1.32 & $(0.98-1.78)$ & 1.32 & $(0.78-2.24)$ \\
\hline Current & ment & & & & & & \\
\hline & $\mathrm{N} / \mathrm{A}$ & 189 & (44) & Ref. & & & \\
\hline & Methadone & 145 & (58) & $\underline{1.71}$ & $(1.25-2.34)$ & $\underline{1.61}$ & $(1.14-2.29)$ \\
\hline & Other & 9 & (43) & $\overline{0.94}$ & $(0.39-2.29)$ & $\overline{1.36}$ & $(0.53-3.54)$ \\
\hline & Buprenorphine & 41 & (44) & 0.97 & $(0.62-1.53)$ & 1.06 & $(0.65-1.72)$ \\
\hline
\end{tabular}


Truong, A., Higgs, P., Cogger, S., Burns, L., Jamieson, L. \& Dietze, P. 2015. Oral Health-Related Quality of Life among an Australian sample of people who inject drugs, Journal of Public Health Dentistry, doi: 10.1111/jphd.12092

Table 3: Distribution of 'extent' scores across key sociodemographic and drug use variables, along with negative binomial regression results.

\begin{tabular}{|c|c|c|c|c|c|}
\hline \multirow{2}{*}{$\begin{array}{l}\mathrm{n}=794 \\
\text { Gender }\end{array}$} & & \multicolumn{2}{|c|}{$\operatorname{IRR}(95 \% \mathrm{CI})$} & \multicolumn{2}{|c|}{$\operatorname{AIRR}(95 \% \mathrm{CI})$} \\
\hline & & & & & \\
\hline & $\begin{array}{l}\text { Female } \\
\text { Male }\end{array}$ & $\begin{array}{l}\text { Ref. } \\
\underline{0.66}\end{array}$ & $(0.51-0.86)$ & $\underline{0.64}$ & $(0.48-0.84)$ \\
\hline \multicolumn{6}{|l|}{ Age } \\
\hline & $<30$ & Ref. & & & \\
\hline & $30-39$ & 1.09 & $(0.70-1.70)$ & 1.05 & $(0.62-1.79)$ \\
\hline & $40+$ & 1.24 & (0.81-1.92) & 1.24 & $(0.63-2.44)$ \\
\hline \multicolumn{6}{|c|}{ Accommodation } \\
\hline & Stable & Ref. & & & \\
\hline & Unstable & 0.81 & $(0.55-1.21)$ & 0.85 & $(0.57-1.26)$ \\
\hline & Homeless & 1.24 & $(0.84-1.82)$ & 1.37 & $(0.93-2.03)$ \\
\hline \multicolumn{6}{|c|}{ Country of birth } \\
\hline & Australia & Ref. & & & \\
\hline & Other & 0.7 & $(0.48-1.02)$ & 0.73 & $(0.49-1.08)$ \\
\hline \multicolumn{6}{|c|}{ Language spoken at home } \\
\hline & English & Ref. & & & \\
\hline & Other & 0.67 & $(0.35-1.29)$ & 0.57 & $(0.29-1.12)$ \\
\hline \multicolumn{6}{|l|}{ ATSI } \\
\hline & No & Ref. & & & \\
\hline & Yes & 1.36 & $(0.97-1.91)$ & 1.17 & $(0.83-1.65)$ \\
\hline \multicolumn{6}{|c|}{ Highest level of education } \\
\hline & $<$ Year 10 & Ref. & & & \\
\hline & Year $10-11$ & 0.82 & $(0.62-1.10)$ & 0.79 & $(0.59-1.05)$ \\
\hline & Year $12 /$ higher/trade & 0.77 & (0.54-1.10) & 0.74 & $(0.51-1.06)$ \\
\hline \multicolumn{6}{|c|}{ Employment } \\
\hline & No & Ref. & & & \\
\hline & Yes & $\underline{0.58}$ & $(0.38-0.87)$ & $\underline{0.64}$ & $(0.42-0.99)$ \\
\hline \multicolumn{6}{|c|}{ Income (average weekly amount) } \\
\hline & $0-249$ & Ref. & & & \\
\hline & $250-399$ & 1.00 & $(0.73-1.37)$ & 1.02 & $(0.74-1.41)$ \\
\hline & $400+$ & 0.91 & $(0.65-1.26)$ & 0.88 & $(0.62-1.24)$ \\
\hline \multicolumn{6}{|c|}{ Age first injected } \\
\hline & Continuous & 1.01 & (0.99-1.03) & 1.02 & $(0.99-1.05)$ \\
\hline \multicolumn{6}{|c|}{ Length of injecting career } \\
\hline & $<10$ years & Ref. & & & \\
\hline & $10-20$ years & 1.36 & $(0.90-2.06)$ & 1.76 & $(1.03-3.01)$ \\
\hline & $>20$ years & 1.22 & $(0.81-1.84)$ & $\overline{1.66}$ & $(0.80-3.45)$ \\
\hline \multicolumn{6}{|c|}{ Drug of choice } \\
\hline & Heroin & Ref. & & & \\
\hline & Other & 1.18 & $(0.87-1.61)$ & 1.45 & $(0.97-2.19)$ \\
\hline & Methamphetamine & 0.75 & $(0.54-1.04)$ & 0.88 & $(0.53-1.46)$ \\
\hline \multicolumn{6}{|c|}{ Drug injected most often last month } \\
\hline & Heroin & Ref. & & & \\
\hline & Other & 0.91 & $(0.68-1.23)$ & 0.89 & $(0.55-1.46)$ \\
\hline & Methamphetamine & 0.76 & $(0.55-1.05)$ & 0.72 & $(0.40-1.28)$ \\
\hline \multicolumn{6}{|c|}{ MA use frequency (last 6 months) } \\
\hline & No use & Ref. & & & \\
\hline & $<$ Fortnightly & 0.91 & $(0.65-1.28)$ & 0.86 & $(0.61-1.22)$ \\
\hline & Fortnightly or more & 0.99 & $(0.74-1.32)$ & 1.34 & $(0.94-1.92)$ \\
\hline \multicolumn{6}{|c|}{ Heroin use frequency (last 6 months) } \\
\hline & No use & Ref. & & & \\
\hline & $<$ Fortnightly & 0.81 & $(0.53-1.24)$ & 0.86 & $(0.56-1.32)$ \\
\hline & Fortnightly or more & 1.15 & $(0.87-1.51)$ & 1.16 & $(0.74-1.83)$ \\
\hline Curren & & & & & \\
\hline & N/A & Ref. & & & \\
\hline & Methadone & 1.21 & $(0.91-1.61)$ & 1.31 & $(0.96-1.77)$ \\
\hline & Other & 0.56 & $(0.24-1.30)$ & 0.79 & $(0.33-1.86)$ \\
\hline & Buprenorphine & 1.12 & $(0.74-1.68)$ & 1.36 & $(0.90-2.07)$ \\
\hline
\end{tabular}

